\title{
PHYSICS AND THE FUTURE
}

$\mathrm{F}^{\mathrm{o}}$ OR the majority of citizens science remains inaccessible. It has little or no place in their school life, their newspapers, their cinemas, their radio, or their literature. Although present-day civilization depends entirely on applied science, even the politicians and rulers, who guide our affairs, share this common unfamiliarity with science. Dramatic events like war, however, in which science is misapplied, forcibly direct attention to man's most powerful tool. If the War of 1914-18 was a chemists' war, the present affliction, with its extensive mechanization, radio propaganda and aeronautical developments is a physicists' war. Aerial bombardment alone might almost be called a nightmare of complex physical problems the solution of which would need the efforts of more than the whole of the country's physicists. In the circumstances, a scarcity of physicists is not surprising. The Board of Education is approaching the problem by offering a number of State bursaries chiefly in physics, engineering and chemistry (see p. 25l).

But the dearth is world-wide. Of the 4,500 American physicists, about 1,400 are already engaged on war work and 600 more are needed within the next year. One hundred others are needed in essential production industries*. The present solution of letting some of the physicists desert the universities is hampering both the training of future physicists and the production of new physics.

If physicists were wanted in large numbers solely in war-time, and then only to assist in the slaughter of vast numbers of citizens of the world, there are many who would care little for the future of physics. But physics is of vital importance in war-time for the very reason that it will be of vital importance in the future peace. Until the biological sciences have developed, applied physics is man's most powerful tool in dealing with his environment. The fact that civilization is at present misapplying the tool means that, in peacetime, it must be used with redoubled energy both to make good the damage done and also to make up for the time lost during war.

What then are the difficulties in providing an adequate supply of physicists? In the first place, physics, like all the sciences, is expensive to teach. In many schools the sciences are still apt to be regarded as 'extras' just as in daily life the sciences are outside most men's experience. Of all the sciences, physics is the most expensive. Cost is therefore a highly relevant factor. Money and

* Rev. Sci. Inst., 12, 177-78 and 247-49 (1941). methods of teaching must be found so that every boy and girl without exception is consciously brought into contact with physical phenomena. Physics will then suffer no neglect, as at present, from ignorance. But not all intelligent boys and girls are potential physicists. Special abilities as well as love of physical phenomena are needed. A mathematical mind, if not technical skill in mathematics, is essential to the physicist in order that he may benefit from the results of mathematical physicists and that he may be able to present his own theoretical problems in suitable form to mathematicians. Then again physics is difficult because it covers not one, but several subjects.

When potential physicists are found they have to be trained. More attention has been given to this process in the United States and in the U.S.S.R. than in Great Britain. Here, expense is again the most significant factor although its influence is subtle. University teaching of physics must be associated with research. But research apparatus is so expensive that little money can be spared for extra non-graduate research assistants and technicians. It is an open secret that a university professor of physics can get more easily the money to pay an extra graduate than a nongraduate member of staff. As a result, junior members of staff are in practice appointed not only for their research abilities but also because their type of research apparatus is already in the department. In a school of research they must in fact play the part of research assistants and technicians, incidentally making apparatus for part of the time which otherwise might be spent in making physies. It would indeed be fortunate if when each new appointment were made research ability and technical experience in a particular branch of physics were combined with equal ability in training physicists.

That no very serious attention is given to the method of training physicists is a result of the comparatively short time of establishment of most physics laboratories. Two other factors are relevant. The reputation of a university physics department as a source of physicists depends upon those few students who, taking to physics as ducks take to water, are almost if not quite independent of the method of training. Then again, until comparatively recently, but few physicists have been used in industry. Conditions have now changed. Physicists whose main task in life is rather to apply than to make physics are, and will continue to be, wanted in increasing numbers. If 
serious consideration were given to their training, no harm would be done to the few born physicists and much help might be given to the production of physicists who would go out into the world and apply physics to man's needs.

Before the War, the average cost of a university research paper in physics was not less than $£ 300$. The average cost of the equipment needed to start work in any one of the specialized branches of the subject was $£ 1,000$. An expenditure of $£ 15,000,000$ a day on equipment for warfare may make the expense of physics seem paltry. Sufficient evidence of poverty-stricken conditions of some physics research can be seen in such papers as appear from time to time in the Journal of Scientific Instruments, where research is described on finding an inexpensive way of carrying out some physical operation for which ready-made but more expensive equipment is already available.

If physicists' contributions to war help to remove ignorance of physics, the money needed for physics in peace-time may be forthcoming. Then will be the time to show that applied physics is as powerful a tool for construction as it is at present for destruction or protection. Even if a university graduate in physics has paid for his training from private sources he will still have cost the community large sums of money. By using his talents together with his training he can repay in service to mankind. Tremendous possibilities lie ahead. One only need be mentioned. At present biology is absent from the education of most men, including physicists. Oficially, the physicist knows nothing of life. When this blind spot has been removed, some physicists will feel drawn to biological problems and the wonderful developments of bioehemistry will be matched by those of biophysies.

The excellent equipment of the physicists in the United States and the U.S.S.R. should be a lesson not yet appreciated in Great Britain, that, generally speaking, the day of phys cs done with sealing wax and tobacco tins is past. Physics is an expensive subject and will become more so as each new development is made and applied to revitalize older branches of the subject. But in return for the cost, physicists can and will repay in service to mankind by making and applying physics and by helping to train the next generation. To help recovery from the tragedy of war every scrap of brain-power will be needed. Given the means, physicists can and will play a vital part in this recovery.

\section{IS MARXISM SCIENCE?}

Marxism : Is it Science?

By Max Eastman. Pp. 343. (London: George Allen and Unwin, Ltd., 1941.) $8 s .6 d$ net.

$\mathrm{M}^{\mathrm{A}}$ AX EASTMAN is a somewhat odd critic of Marxism. He appears to accept at the outset most of the aspects of Marxism that have made it anathema to orthodox opinion. Not only does he agree with the economic analysis Marx made of the capitalist system, but even with the revolutionary application of this analysis by Lenin. But this seeming agreement covers a fundamental objection to the whole method of Marxism. He is an inveterate opponent of dialectical materialism, not because of its results, but because it represents a type of thinking profoundly different from his own. Max Eastman is a perfect type of nineteenthcentury intellectual radical, a believer in common sense and engineering, with a violent antipathy to all forms of philosophy and religion. The book itself represents only one stage in retrogression towards older views. Since it was written, Max Eastman, from being a critic of Marxist logic and philosophy, has moved to a rejection of Marxist economic theory and political ideas.

In this book his fundamental objection to
Marxism is that it is religious. Religion he defines as the belief "that the external world, or some power in it, is interested in the interests of men. The religious believer persuades himself that the world is softer than it is, and that we know more about it than we do". And Marxists are religious because "they cherish a belief that the external universe is evolving with reliable, if not divine, necessity, in exactly the direction they want it to go". What he would like instead is a stern belief in the indifference of the world, and what he calls the "engineering approach" to social problems.

"An engineer wishing to convert a given form of society into a more satisfactory one, would begin by making a very rough outline of the kind of society he proposed to build. With that rough blueprint in mind he would examine the existing society, and he would also examine all past societies, and find out what are the forces which control them and the general laws of their change. When he had finished that investigation and acquired that knowledge, he would draw up a procedure or plan of action, a scheme for getting the thing moving (supposing that his investigations had proven it possible) in the direction of his proposal." 